Review Article

\title{
Topical Herbal Application in the Management of Atopic Dermatitis: A Review of Animal Studies
}

\author{
Younghee Yun, ${ }^{1,2}$ Kyuseok Kim, ${ }^{3}$ Inhwa Choi, ${ }^{2,3}$ and Seong-Gyu Ko ${ }^{4}$ \\ ${ }^{1}$ Department of Dermatology of Korean Medicine, College of Korean Medicine, Graduate School of Kyung Hee University, \\ Seoul 130-701, Republic of Korea \\ ${ }^{2}$ Department of Dermatology of Korean Medicine, Kyung Hee University Hospital at Gangdong, No. 149 Sangil-dong, \\ Gangdong-gu, Seoul 134-090, Republic of Korea \\ ${ }^{3}$ Department of Ophthalmology \& Otorhinolaryngology \& Dermatology of Korean Medicine, College of Korean Medicine, \\ Kyung Hee University, Seoul 130-701, Republic of Korea \\ ${ }^{4}$ Department of Preventive Medicine, College of Korean Medicine, Kyung Hee University, Seoul 130-701, Republic of Korea
}

Correspondence should be addressed to Inhwa Choi; inhwajun@hanmail.net

Received 4 February 2014; Revised 23 May 2014; Accepted 25 May 2014; Published 15 June 2014

Academic Editor: Chang Shik Yin

Copyright (C) 2014 Younghee Yun et al. This is an open access article distributed under the Creative Commons Attribution License, which permits unrestricted use, distribution, and reproduction in any medium, provided the original work is properly cited.

\begin{abstract}
Herbs are widely used in the treatment of atopic dermatitis (AD) in Eastern Asian countries, and certain herbs regarded have anti-inflammatory properties that can help with $\mathrm{AD}$. With the goal of developing a topical herbal agent for $\mathrm{AD}$, we conducted a systematic review of in vivo studies of AD-like skin models for screening potential herbs. Searches were conducted from PubMed and EMBASE. After all, 22 studies were included for this review. We judged most of the domains of all studies to be at unclear risk of bias. Among 22 included studies, 21 herbs have been reported to reduce AD-like skin lesions in mouse models by suppressing Th2 cell response. Our findings may offer potential herbs for the topical application treatment of AD.
\end{abstract}

\section{Introduction}

There are many chemical substances that have been derived from plants for use as drugs, and these include some of the most utilized drugs such as aspirin, atropine, digoxin, ephedrine, morphine, quinine, and taxol. The latest version of the Dictionary of Natural Products (DNP; http://dnp.chemnetbase.com/) has just over 260,000 entries. Over the past decades, natural sauces have only taken a secondary role in drug discovery and development after the advent of molecular biology and combinatorial chemistry. However, as a basis for drug development, a new interest in the role of natural sauces has been concentrated, because various "-omics" technologies now allow scientists to detail the exact biological effects of natural sauces [1].

Atopic dermatitis (AD) is a chronic inflammatory skin disease with an increasing prevalence in industrialized countries. $\mathrm{AD}$ is characterized by pruritus; eczematous lesions accompanied by excessive infiltration of inflammatory cells such as lymphocytes, macrophages, and granulated mast cells in the skin lesions; eosinophilia in the peripheral blood; and high levels of serum immunoglobulin IgE. Although the pathogenesis of $\mathrm{AD}$ has not yet been fully understood, genetic, environmental, pharmacological, psychological, immunological, and skin barrier dysfunction factors are believed to contribute to the underlying pathogenic mechanisms [2-4].

Topical steroids are commonly used to treat moderateto-severe $\mathrm{AD}$, but long-term use of steroids at high concentrations is associated with a number of side effects [5]. Among various natural sources such as plants, animals, or microorganisms, herbs are widely used in the treatment of atopic dermatitis (AD) in Eastern Asian countries, and certain herbs regarded have anti-inflammatory properties that can help with AD. Our interest is to develop a safe and curative herb derived agent for $\mathrm{AD}$ using medical knowledge and clinical experience of herbal medicine combining with molecular biology and combinatorial chemistry technologies. 
TABle 1: Search strategy for PubMed.

\begin{tabular}{ll}
\hline & "Herbal Medicine" [MeSH term] or "Herbals" [MeSH terms] or "Herbals as Topic" [MeSH terms] or "Plant \\
& $\begin{array}{l}\text { Extracts" [MeSH terms] or "Drugs, Chinese Herbal" [MeSH term] or "Plants, Medicinal" [MeSH terms] or } \\
\text { "Ethnobotany" [MeSH term] or "Medicine, Traditional" [MeSH Terms] or "Phytotherapy" [MeSH terms] or } \\
\text { "Herb" [tiab] or "Extract" [tiab] or "Extracts" [tiab] or "Chinese medicine" [tiab] or "Korean medicine" [tiab] or } \\
\text { "Kampo" [tiab] }\end{array}$ \\
& "Nermatitis, atopic" [MeSH Terms] or "Atopic dermatitis" [title/abstract] or "Eczema, Atopic" [title/abstract] \\
Disease of interest & Using "Animal search filter" [8] \\
Animal species & Not included in the search strategy \\
Outcome measures & Full text available AND English AND Published in the last 5 years \\
\hline
\end{tabular}

Recently, since Sandercock and Roberts drew attention to the need for more animal studies before beginning studies in human patients [6], there has been an increasing interest in the systematic reviews of research involving animals.

Systematic reviews can aid in the development of more effective therapeutic agents for $\mathrm{AD}$ by extrapolating the results of animal studies to humans [7]. We performed a systematic review with this goal in mind and our objectives were (i) to screen topically applicable herbs for $\mathrm{AD}$, (ii) to suggest potential mechanisms of action of topical herbal application in animal models of $\mathrm{AD}$, and (iii) to ascertain the conditions of animal experiments used in the studies.

\section{Methods}

\subsection{Criteria for Considering Studies for This Review}

\subsubsection{Inclusion Criteria}

(i) Studies on the use of topical herbs for $\mathrm{AD}$ in animal models

(ii) Published between 2009 and 2013

(iii) Full text available

(iv) Article in English.

\subsubsection{Exclusion Criteria}

(i) Not related to $\mathrm{AD}$ or allergic dermatitis

(ii) Not an animal study

(iii) Animal cell studies

(iv) Not an investigational study of herbs

(v) Not an investigational study of herbs alone

(vi) Studies investigating compounds isolated from herbs

(vii) Use of fermented herbs by Lactobacillus plantarum and so forth

(viii) Studies investigating oils from herbs

(ix) Pharmacoacupuncture

(x) Preexisting herbal drugs

(xi) Anal, intraperitoneal, or oral administration of herbs

(xii) Herbal mixtures

(xiii) Biomarkers not used as outcome measurements.
TABLE 2: Search strategy for EMBASE.

\begin{tabular}{ll}
\hline Intervention/exposure & Medical plant [EMTREE] \\
Disease of interest & Atopic dermatitis [EMTREE] \\
Outcome measures & Not included in the search strategy \\
& $\begin{array}{l}\text { English AND Published from 2009 to } \\
\text { 2013 AND (animal experiment OR } \\
\text { animal tissue OR animal model) }\end{array}$ \\
\hline
\end{tabular}

\subsection{Search Methods for Identification of Studies}

2.2.1. Data Sources and Searches. Literature searches were performed using PubMed and EMBASE databases. Search terms contained three components: (A) intervention/exposure, (B) disease of interest, and (C) animal species, with adjustments made for the different databases. Herbs were defined as plants, part of plants, or plant extracts that are used for medical purposes. Since the administration method of the herbs, as well as the outcome measures, was commonly described in the main article and rarely indexed in many papers, we excluded the administration method and outcome measures in the search strategy. For identification of $\mathrm{MeSH}$ terms, we used the PubMed thesaurus and the MeSH database, while we used EMTREE terms for searches using EMBASE. To identify all animal studies in PubMed, we used the "Animal search filter" that Hooijmans et al. [8] designed, while we used the filters in EMBASE. The full lists of search terms are presented in Tables 1 and 2 .

2.2.2. Selection of Studies. Two authors (Yun and Kim) independently conducted the database searches. Duplicate articles were removed by the first author (Yun). Moreover, the references lists of review articles on relevant topics were manually searched by the two authors. For identifying eligibility of each study, the two authors read all potentially relevant articles. Disagreements were resolved by discussions with the corresponding author (Choi and Ko).

\section{Results}

3.1. Identification of Studies. After adding the search results from PubMed $(n=165)$ and EMBASE $(n=33)$, duplicate articles $(n=24)$ were removed. References lists in review articles $(n=8)$ were searched but did not result in any 


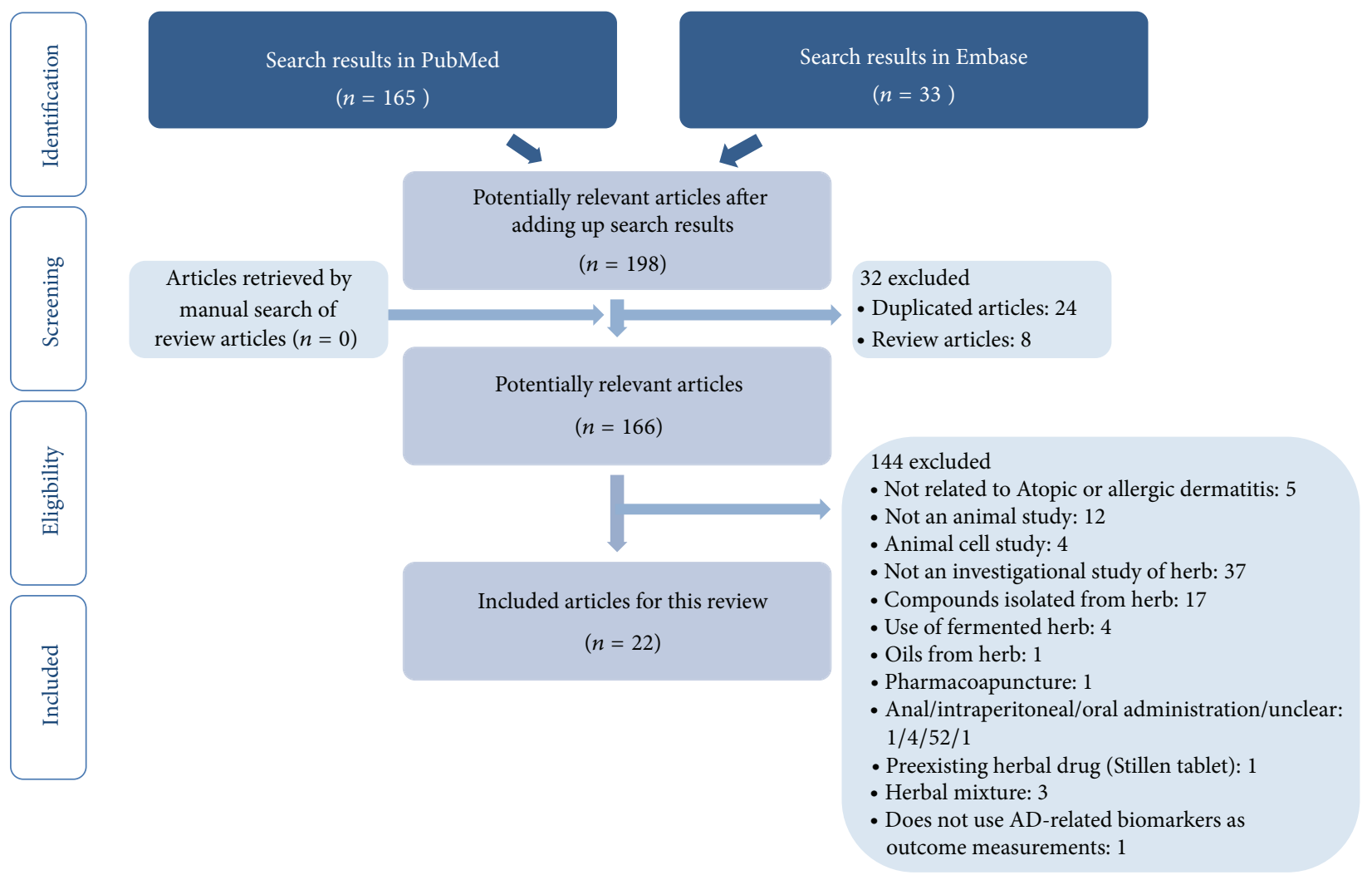

FIGURE 1: Flowchart of the study selection process.

articles being retrieved. From the potentially relevant articles ( $n=166$ ), we excluded 144 articles based on the predefined exclusion criteria, resulting in a total of 22 studies being included in this review (Figure 1).

3.2. Risk of Bias. Figure 2 shows the study quality checklist items reported for each included study, including random allocation to treatment groups $(n=8,36.4 \%)$, compliance with animal welfare regulations $(n=22,100 \%)$, and statements of a potential conflict of interest $(n=16$, $72.7 \%$ ). None of the studies reported allocation concealment, examiner blinding, sample size calculation, and if results were based on analysis of the intent-to-treat population.

3.3. Basic Characteristics and Investigated Herbs in the Included Studies. Twenty-one studies were conducted in Korea and one was conducted in Japan. In two studies, herbs of the genus Chrysanthemum were investigated. Otherwise, there were no studies investigating the same herb (Table 4). Herbal extracts were prepared using ethanol, water, methanol, butanol, chloroform, 1,3-butylene glycol, or indirect heat.

3.4. Animal Models Used in the Included Studies. All studies used mice to investigate topical herbal application in an in vivo setting. The NC/Nga mouse $(n=16)$ was the most frequently used mouse model in these studies, followed by $\mathrm{BALB} / \mathrm{c}(n=4), \mathrm{C} 57 \mathrm{BL} / 6(n=1)$, and hairless mice $(n=1)$.
The methods used for induction of AD-like skin lesions varied depending on the study. Repeated cutaneous application of chemical allergens and house dust mite allergens was used in 15 and 10 studies, respectively. Skin injury by stripping using surgical tape was used in 2 studies. For barrier disruption, sodium dodecyl sulfate (SDS) was applied to the lesions in 8 studies. Dorsal skin, ears, or a combination of dorsal skin and ears was used in most of the studies (Table 3 ).

3.5. Main Outcomes Investigated, Results, and Suggested Mechanisms of Action. In most of the studies, clinical symptoms, serum IgE levels, and Th1- and/or Th2-related cytokines and/or chemokines were assessed as outcome measurements (Table 4). The clinical severity of dermatitis was scored, and severity was found to have decreased after topical herbal application in 15 studies. Epidermal, dermal, or ear thickness was measured and was found to be decreased in 13 studies, indicating a decrease in the severity of the inflammatory process. Frequency of scratching was measured by counting scratching episodes in 5 studies, either directly or by reviewing videos of the animal. After topical herbal application, the frequency of scratching was decreased in all 5 studies.

Elevated serum IgE levels are important characteristics of AD. Serum or plasma IgE levels were measured in 21 studies, and, in 20 of these, serum or plasma IgE levels were decreased after the topical herbal application. However, in one study [9], neither topical Rehmannia glutinosa extract nor tacrolimus reduced the increased serum IgE levels after 


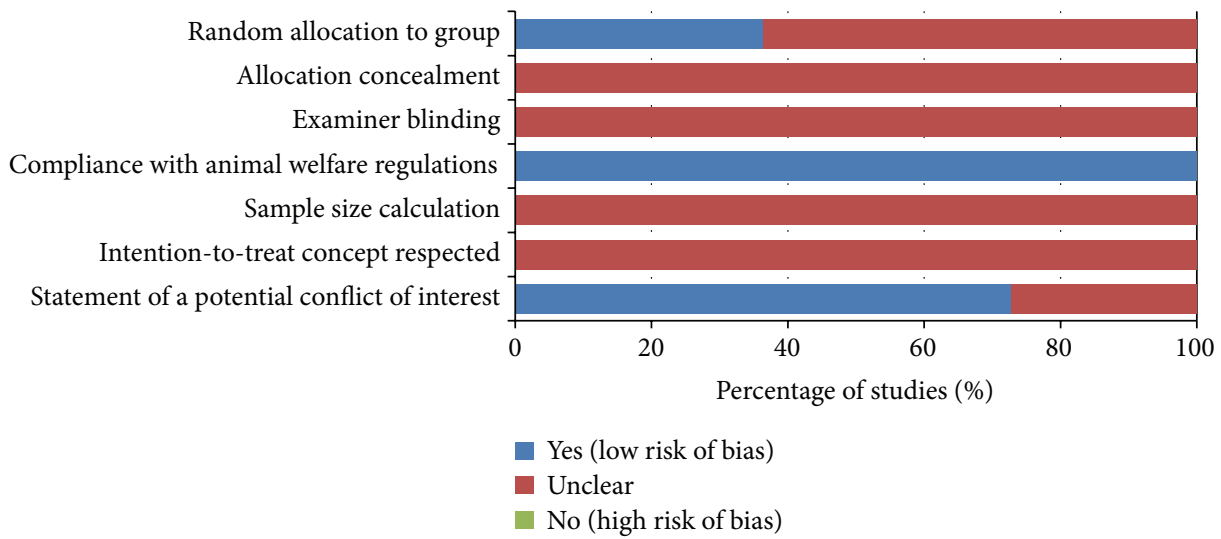

FIgURE 2: Risk of bias in the studies.

TABLE 3: Basic characteristics of the animal models used in the included studies.

\begin{tabular}{|c|c|c|c|c|}
\hline Study & Sex/model species & Induction of AD-like skin & Barrier disruption & Investigation site \\
\hline Qi et al. [27] & F/hairless mouse & DNCB & $\mathrm{N} / \mathrm{A}$ & Dorsal skin \\
\hline Lee et al. [14] & M/NC/Nga mouse & DfE & SDS & Dorsal skin, ears \\
\hline Choi et al. [15] & F/NC/Nga mouse & DfE & $\mathrm{N} / \mathrm{A}$ & Dorsal skin \\
\hline Sohn et al. [28] & $\mathrm{M} / \mathrm{BALB} / \mathrm{c}$ mouse & $\mathrm{DNCB}$ & $\mathrm{N} / \mathrm{A}$ & Dorsal skin \\
\hline Wu et al. [29] & $\mathrm{M} / \mathrm{NC} / \mathrm{Nga}$ mouse & DNFB & $\mathrm{N} / \mathrm{A}$ & Dorsal skin \\
\hline Yang et al. [16] & F/NC/Nga mouse & $\mathrm{DNCB}$ & N/A & Dorsal skin, ears \\
\hline Sung et al. [30] & M/NC/Nga mouse & DfE & SDS & Dorsal skin, ears \\
\hline Nam et al. [31] & $\mathrm{M} / \mathrm{C} 57 \mathrm{BL} / 6$ mouse & DNFB & $\mathrm{N} / \mathrm{A}$ & Abdominal skin, ears \\
\hline Choi et al. [24] & $\mathrm{F} / \mathrm{BALB} / \mathrm{c}$ mouse & $\mathrm{DNCB}, \mathrm{DfE}$, and skin injury & N/A & Ears \\
\hline Sung et al. [9] & M/NC/Nga mouse & DfE & SDS & Dorsal skin, ears \\
\hline Lee et al. [22] & $\mathrm{M} / \mathrm{NC} / \mathrm{Nga}$ mouse & DfE & SDS & Dorsal skin, ears \\
\hline Ngatu et al. [17] & M/NC/Nga mouse & TNCB & $\mathrm{N} / \mathrm{A}$ & Abdominal skin, ears \\
\hline Yang et al. [18] & F/NC/Nga mouse & $\mathrm{DNCB}$ & SDS & Dorsal skin, ears \\
\hline Hwang et al. [25] & $\mathrm{F} / \mathrm{BALB} / \mathrm{c}$ mouse & DNCB, DfE, and skin injury & $\mathrm{N} / \mathrm{A}$ & Ears \\
\hline Choi et al. [32] & M/NC/Nga mouse & $\mathrm{DNCB}$ & $\mathrm{N} / \mathrm{A}$ & Dorsal skin, ears \\
\hline Sung et al. [33] & $\mathrm{M} / \mathrm{NC} / \mathrm{Nga}$ mouse & DNCB and DfE & SDS & Dorsal skin, ears \\
\hline Kang and Shin [34] & $\mathrm{M} / \mathrm{NC} / \mathrm{Nga}$ mouse & DNCB & $\mathrm{N} / \mathrm{A}$ & Dorsal skin \\
\hline Sung et al. [35] & $\mathrm{M} / \mathrm{NC} / \mathrm{Nga}$ mouse & DfE & SDS & Dorsal skin, ears \\
\hline Park et al. [10] & F/NC/Nga mouse & DNCB & $\mathrm{N} / \mathrm{A}$ & Dorsal skin, right ear \\
\hline Yang et al. [36] & $\mathrm{M} / \mathrm{NC} / \mathrm{Nga}$ mouse & DfE & $\mathrm{N} / \mathrm{A}$ & Dorsal skin, ears \\
\hline Kim et al. [37] & F/BALB/c mouse & DNCB & SDS & Dorsal skin \\
\hline Choi et al. [38] & M/NC/Nga mouse & DNCB & $\mathrm{N} / \mathrm{A}$ & Dorsal skin, ears \\
\hline
\end{tabular}

DNCB: 1-chloro-2,4-dinitrobenzene, DfE: D. farinae extract, DNFB: 2,4-dinitrofluorobenzene, TNCB: 2,4,6-trinitrochlorobenzene, N/A: not applicable, SDS: sodium dodecyl sulfate, $\mathrm{M}$ : male, and F: female.

allergen sensitization, although they both suppressed the expression of interleukin- (IL-) 4 mRNA in the ear lesions. Antigen-specific IgE levels were measured in two studies, both of which used house dust mite allergen and DNCB to induce AD-like skin lesions.

Most of the included studies investigated the Th2response suppressing effects and/or Thl-response modulating effects upon topical herbal application in the AD-like mouse models. In 14 studies, only Th2-related biomarkers were measured, while both Th1- and Th2-related biomarkers were measured in nine studies. In all 21 studies that measured Th2 responses, topical herbal application resulted in decrease of Th2-related cytokines, chemokines, proinflammatory factors, and adhesion molecules. Conversely, among the eight studies that measured interferon- (IFN-) $\gamma$, topical herbal application resulted in increased IFN- $\gamma$ levels in two studies, decreased levels in five studies, and no induced changes in one study. Interestingly, in one study [10], Chrysanthemum indicum L. decreased both Th1 (IFN- $\gamma$ ) and Th2 cytokines (IL- 4 and IL13); however, the ratio of Th1 to Th2 cytokines was increased by herbal application.

\section{Discussion}

Herbal medicine is the use of medicinal plants for prevention and treatment of disease. Herbs and their derivatives have been, and continue to be, rich sources for drug discovery. Recently, results from several studies have indicated that 
TABLE 4: Investigated herbs, results, and suggested mechanisms of action in the included studies.

\begin{tabular}{|c|c|c|c|}
\hline Ref. number & Herb & Outcomes and results & Suggested mechanisms \\
\hline$[14]$ & Bambusae caulis & $\begin{array}{l}\text { TEWL } \downarrow \\
\text { serum IgE } \downarrow \text { eosinophil } \downarrow \\
\text { spleen IFN- } \gamma \uparrow \text { TNF- } \alpha \downarrow \text { IL- } 4 \downarrow \text { IL-13 } \downarrow\end{array}$ & $\begin{array}{l}\text { Suppression of Th2 response and } \\
\text { promotion of Th1 response }\end{array}$ \\
\hline$[15]$ & $\begin{array}{l}\text { Broussonetia } \\
\text { kazinoki }\end{array}$ & $\begin{array}{l}\text { Plasma IgE } \downarrow \text { IL- } 4 \downarrow \\
\text { skin mast cell } \downarrow\end{array}$ & Suppression of Th2 response \\
\hline$[28]$ & Alnus japonica & $\begin{array}{l}\text { Clinical score } \downarrow \\
\text { serum IgE } \downarrow \text { eosinophil } \downarrow \\
\text { skin IL- } 4 \downarrow \text { IL-5 } \downarrow \text { IL-13 } \downarrow \text { iNOS } \downarrow \text { COX- } 2 \downarrow\end{array}$ & Suppression of Th2 response \\
\hline$[29]$ & $\begin{array}{l}\text { Korean red } \\
\text { ginseng }\end{array}$ & $\begin{array}{l}\text { Scratching } \downarrow \\
\text { serum IgE } \downarrow \text { IL- } 4 \downarrow \text { IL-10 } \downarrow\end{array}$ & Suppression of Th2 response \\
\hline$[16]$ & $\begin{array}{l}\text { Cordyceps } \\
\text { bassiana }\end{array}$ & $\begin{array}{l}\text { Clinical score } \downarrow \text { epidermal thickness } \downarrow \\
\text { serum IgE } \downarrow \text { histamine } \downarrow \text { skin IFN- } \gamma \downarrow \text { IL- } 4 \downarrow \text { mast cell } \downarrow\end{array}$ & $\begin{array}{l}\text { Suppression of both Th1 and Th2 } \\
\text { responses }\end{array}$ \\
\hline$[30]$ & $\begin{array}{l}\text { Chelidonium } \\
\text { majus }\end{array}$ & $\begin{array}{l}\text { Clinical score } \downarrow \text { ear thickness } \downarrow \text { scratching } \downarrow \\
\text { serum IgE } \downarrow \text { IL- } 4 \downarrow \text { TNF- } \alpha \downarrow\end{array}$ & Suppression of Th2 response \\
\hline$[31]$ & $\begin{array}{l}\text { Cinnamomum } \\
\text { cassia }\end{array}$ & $\begin{array}{l}\text { Serum IgE } \downarrow \text { histamine } \downarrow \text { TNF- } \alpha \downarrow \\
\text { skin IL- } 4 \downarrow \text { TNF- } \alpha \downarrow \text { TARC } \downarrow\end{array}$ & Suppression of Th2 response \\
\hline$[24]$ & $\begin{array}{l}\text { Terminalia } \\
\text { chebula Retzius }\end{array}$ & $\begin{array}{l}\text { Ear thickness } \downarrow \\
\text { skin inflammatory cells } \downarrow \text { eosinophils } \downarrow \\
\text { ear IL-31 } \downarrow \text { T-bet positive cell } \uparrow \text { MMP-9 } \downarrow\end{array}$ & $\begin{array}{l}\text { Suppression of Th2 response and } \\
\text { promotion of Th1 response }\end{array}$ \\
\hline$[9]$ & $\begin{array}{l}\text { Lindera } \\
\text { obtusiloba }\end{array}$ & $\begin{array}{l}\text { Ear thickness } \downarrow \\
\text { serum IgE } \downarrow \text { DfE specific IgE } \downarrow \text { histamine } \downarrow \\
\text { ear mast cell } \downarrow \text { IL- } 4 \downarrow \text { IL-13 } \downarrow \text { IL-31 } \downarrow \text { TNF- } \alpha \downarrow\end{array}$ & Suppression of Th2 response \\
\hline$[22]$ & $\begin{array}{l}\text { Rehmannia } \\
\text { glutinosa }\end{array}$ & $\begin{array}{l}\text { Clinical score } \downarrow \text { ear thickness } \downarrow \\
\text { serum IgE } \uparrow \text { histamine } \downarrow \\
\text { ear IL- } 4 \downarrow \text { TNF- } \alpha \downarrow \text { TARC } \downarrow \text { MDC } \downarrow \text { RANTES } \downarrow \text { ICAM- } 1 \downarrow \\
\text { VCAM- } 1 \downarrow\end{array}$ & Suppression of Th2 response \\
\hline$[17]$ & $\begin{array}{l}\text { Angelicae } \\
\text { Dahuricae Radix }\end{array}$ & $\begin{array}{l}\text { Clinical score } \downarrow \\
\text { plasma IgE } \downarrow \text { histamine } \downarrow\end{array}$ & Suppression of Th2 response \\
\hline$[18]$ & $\begin{array}{l}\text { Vernonia } \\
\text { amygdalina }\end{array}$ & $\begin{array}{l}\text { Clinical score } \downarrow \text { ear thickness } \downarrow \text { scratching } \\
\text { serum IgE } \downarrow \text { IL- } 4 \downarrow \text { IL-5 } \downarrow \text { MCP- } 1 \downarrow \text { eotaxin } \downarrow\end{array}$ & Suppression of Th2 response \\
\hline$[25]$ & $\begin{array}{l}\text { Chrysanthemum } \\
\text { boreale Makino }\end{array}$ & $\begin{array}{l}\text { Clinical score } \downarrow \text { ear thickness } \downarrow \text { scratching } \downarrow \\
\text { serum IgE } \downarrow \text { TNF- } \alpha \downarrow \text { IL- } 4 \downarrow\end{array}$ & Suppression of Th2 response \\
\hline$[32]$ & $\begin{array}{l}\text { Mycelium of } \\
\text { Phellinus linteus }\end{array}$ & $\begin{array}{l}\text { Clinical score } \downarrow \text { ear thickness } \downarrow \\
\text { serum IgE } \downarrow \text { DfE specific IgE } \downarrow \text { total IgG- } \\
\text { ear IL-12 IFN- } \gamma \downarrow \text { IL-4 } 4 \text { IL-5 } \downarrow \text { IL-10 } \downarrow \text { IL-13 } \downarrow \text { TNF- } \alpha \downarrow \\
\text { CCL4 } \downarrow \text { CCL22 } \downarrow \text { CCL17- CCL20- eotaxin- IL-2 } \downarrow\end{array}$ & $\begin{array}{l}\text { Suppression of both Th1 and Th2 } \\
\text { responses }\end{array}$ \\
\hline$[33]$ & Psidium guajava & $\begin{array}{l}\text { Clinical score } \downarrow \\
\text { serum IgE } \downarrow \text { TARC } \downarrow \text { IL-10 } \\
\text { ear IFN- } \gamma \downarrow \text { TNF- } \alpha \downarrow \text { IL- } 4 \downarrow \text { IL-5 } \downarrow \text { IL-13 } \downarrow\end{array}$ & $\begin{array}{l}\text { Suppression of both Th1 and Th2 } \\
\text { responses and upregulation of } \\
\text { IL-10 }\end{array}$ \\
\hline$[34]$ & $\begin{array}{l}\text { Drynaria } \\
\text { fortunei }\end{array}$ & $\begin{array}{l}\text { Clinical score } \downarrow \text { ear thickness } \downarrow \\
\text { serum IgE } \downarrow \text { IgG1 } \downarrow \text { IgG2a- IL- } 4 \downarrow \text { IL-6 } \downarrow \text { TNF- } \alpha \downarrow \\
\text { ear IFN- } \gamma-\text { IL- } 4 \downarrow \text { TNF- } \alpha \downarrow \text { IL-6 } \downarrow \text { ICAM-1- VCAM-1 }\end{array}$ & Suppression of Th2 response \\
\hline$[35]$ & $\begin{array}{l}\text { Schisandra } \\
\text { chinensis }\end{array}$ & $\begin{array}{l}\text { Clinical score } \downarrow \text { scratching } \downarrow \\
\text { serum IgE } \downarrow \text { IgM } \downarrow \text { histamine } \downarrow \\
\text { skin histamine receptors } \downarrow \text { spleen IL-4 } \downarrow \text { IL-5 } \downarrow \text { FceRI } \beta \downarrow\end{array}$ & Suppression of Th2 response \\
\hline$[10]$ & Illicium verum & $\begin{array}{l}\text { Clinical score } \downarrow \text { ear thickness } \downarrow \\
\text { serum IgE } \downarrow \text { histamine } \downarrow \text { IL- } 6 \downarrow \text { ICAM- } 1 \downarrow \\
\text { ear IFN- } \gamma \uparrow \text { IL- } 4 \downarrow \text { IL-6 } 6 \downarrow \text { TNF- } \alpha \downarrow \text { TARC } \downarrow \text { RANTES } \downarrow \\
\text { ICAM- } 1 \downarrow \text { VCAM- } 1 \downarrow\end{array}$ & $\begin{array}{l}\text { Suppression of Th2 response and } \\
\text { promotion of Th1 response }\end{array}$ \\
\hline$[36]$ & $\begin{array}{l}\text { Chrysanthemum } \\
\text { indicum L. }\end{array}$ & $\begin{array}{l}\text { Clinical score } \downarrow \text { ear thickness } \downarrow \\
\text { serum IgE } \downarrow \text { IgG1 } \downarrow \text { IFN- } \gamma \downarrow \text { IL- } 4 \downarrow \\
\text { skin eosinophil } \downarrow \text { mast cell } \downarrow \text { IFN- } \gamma \downarrow \text { IL- } 4 \downarrow \text { IL-13 } \downarrow \\
\text { IL- } 4: \text { IFN- } \gamma \text { ratio } \downarrow\end{array}$ & $\begin{array}{l}\text { Suppression of both Th1 and Th2 } \\
\text { responses and balancing of } \\
\text { Th1/Th2 cell responses }\end{array}$ \\
\hline
\end{tabular}


TABLE 4: Continued.

\begin{tabular}{|c|c|c|c|}
\hline Ref. number & Herb & Outcomes and results & Suggested mechanisms \\
\hline [37] & Catalpa ovata & $\begin{array}{l}\text { Clinical score } \downarrow \\
\text { serum IgE } \downarrow \\
\text { skin mast cell } \downarrow \text { IL- } 4 \downarrow \text { IL-5 } \downarrow \text { IL-6 } \downarrow \text { IL-13 } \downarrow \text { IL-1b } \downarrow \\
\text { TNF- } \alpha \downarrow\end{array}$ & Suppression of Th2 response \\
\hline$[38]$ & $\begin{array}{l}\text { Astragalus } \\
\text { membranaceus }\end{array}$ & $\begin{array}{l}\text { Epidermal thickness } \downarrow \text { dermal thickness } \downarrow \\
\text { serum IgE } \downarrow \text { IL-4 } 4 \text { IL-5 } \downarrow \text { IL-6 } \downarrow \text { IL-13 } \downarrow \text { TNF- } \alpha \downarrow \\
\text { skin NF- } \kappa \text { B } \downarrow\end{array}$ & Suppression of Th2 response \\
\hline$[11]$ & Pleurotus eryngii & $\begin{array}{l}\text { Clinical score } \downarrow \text { ear thickness } \downarrow \\
\text { serum IgE } \downarrow \text { TARC } \downarrow \\
\text { skin mast cell } \downarrow \text { ear IFN- } \gamma \downarrow \text { TNF- } \alpha \downarrow \text { IL- } 4 \downarrow \text { IL-5 } \downarrow \text { IL-13 } \downarrow\end{array}$ & $\begin{array}{l}\text { Suppression of both Th1 and Th2 } \\
\text { responses }\end{array}$ \\
\hline
\end{tabular}

“-”: no change, TEWL: transepidermal water loss, Ig: immunoglobulin, IFN: interferon, IL: interleukin, TNF: tumor necrosis factor, iNOS: inducible nitric oxide synthase, COX: cyclooxygenase, TARC: thymus and activation-regulated chemokine, MMP: matrix metalloproteinase, MDC: macrophage-derived chemokine, RANTES: regulated on activation normal T-cell expressed and secreted, ICAM: intercellular adhesion molecule, VCAM: vascular adhesion molecule, MCP: monocyte chemoattractant protein, CCLCC: chemokine ligand, FceRI: high-affinity IgE receptor, and NF- $\kappa$ B: nuclear factor- $\kappa$ B.

patients with AD may benefit from herbal medicines [1113]. Certain herbs are regarded to have anti-inflammatory properties that can reduce the symptoms of $\mathrm{AD}$. In Asian herbal medicine, herbs are categorized according to their functions. One such group of categorized herbs is named the clear heat drug group (凊熱藥), and these herbs can be used for treating fever, infectious disease, and inflammatory conditions. Among the included 22 studies, seven studies [9, 10, 14-18] investigated herbs belonging to the clear heat drug group. Among these seven studies, two studies investigated herbs of the genus Chrysanthemum.

Since multiple genetic and environmental factors may underlie $\mathrm{AD}$, the notion of developing a single comprehensive animal model is unrealistic [19]. Since the description of the $\mathrm{Nc} / \mathrm{Nga}$ mouse as the first spontaneously occurring model of AD in 1997 [20], a number of mouse models have been developed. They can be classified into three groups: (1) models induced by epicutaneous application of sensitizers, (2) mice that spontaneously develop AD-like skin lesions, and (3) transgenic mice that either overexpress or lack selective molecules [21].

$\mathrm{NC} / \mathrm{Nga}$ mice were used in 16 of the analyzed studies. These mice are free of dermatitis in pathogen-free conditions but develop a spontaneous AD-like eruption when conventionally housed, and they have historically been viewed as one of the best animal models for assessing this condition [19]. In other studies, models induced by epicutaneous application of sensitizers were used. However, none of the included studies used genetically engineered mouse models.

In most of the included studies, clinical symptoms, serum IgE levels, and Th1- and/or Th2-related cytokines and/or chemokines were measured as outcome measurements. Based on the decreased clinical scores, ear or epidermal thickness, scratching behaviors, and histological inflammations after herbal application, it can be hypothesized that topical herbal application has anti-inflammatory effects. However, we could not conduct a meta-analysis to integrate quantitative analyses, since the studies included in our study all investigated different types of herbs.

Elevated serum IgE levels are an important feature of AD. Several studies have demonstrated that serum IgE levels are elevated in patients with $\mathrm{AD}$; furthermore, serum $\mathrm{IgE}$ levels have been shown to be elevated in NC/Nga mice with AD-like skin lesions [20]. Among the 22 included studies, serum or plasma IgE levels were measured in 21 studies, and, in 20 studies, serum or plasma IgE levels were decreased after herbal treatment. However, in one study [9], neither topical application of Rehmannia glutinosa extract nor tacrolimus reduced the increased serum IgE levels after allergen sensitization, although they both suppressed the expression of IL-4 mRNA in the ear lesions and serum. The authors discussed two possible reasons for this observation: (i) that locally expressed IL-4 in the ear lesions did not contribute to systemic IgE production or (ii) that, in a shortterm study with topical herbal application, effects on serum IgE may not be observed [22]. However, we noted that the authors did not measure the levels of allergen-specific IgE, and, in general, total IgE concentrations are a relatively crude method of detecting allergic disorders, since normal values do not exclude the presence of allergic disease, particularly to a single allergen, and since elevated levels of total IgE can be found in many patients with no evidence of allergy [23].

Conversely, both total and allergen-specific IgE levels were measured and found to be decreased after topical application of water-soluble extract of Lindera obtusiloba and Phellinus linteus in two studies, which used both house dust mite allergens and DNCB to induce AD-like skin lesions [24, 25]. Furthermore, water-soluble extract of $P$. linteus did not affect the total IgG levels, and it was found to be more potent than ceramide in reducing mite-specific IgE levels. These data suggest that certain herbs can suppress allergic responses in an allergen-specific manner. Nevertheless, immunological and clinical parameters for the assessment of antigenspecific immune responses were not measured in most of the studies.

Both Th1- and Th2-type cytokines contribute to the pathogenesis of $\mathrm{AD}$, and their expression patterns are not mutually exclusive [2]. Th2 cytokines such as IL-4, IL-5, and IL-13 play key roles in the hyperproduction of IgE, whereas Th1 cytokines, especially IFN- $\gamma$, are strong inhibitors of IgE synthesis, Th2 cell proliferation, and IL-4 receptor expression on T-cells [26]. Development of AD is induced by Th2type responses, while the chronic inflammatory responses are dominantly mediated by Th1-type reactions. 
Among the 22 included studies, 21 herbs were reported to reduce $\mathrm{AD}$-like skin lesions in mouse models by suppressing Th2 cell response with or without balancing of the Th1/Th2 cell response. In eight studies, Thl cytokines were measured and showed different results. Based on this review, it seems that investigators mainly assess Th1- and Th2-related mechanisms to explain the anti-inflammatory effects of herbs.

In the present study, out of 166 potential studies, we identified 22 studies that met all the selection criteria. It showed that there is room for methodological improvement in the studies. Most studies were at an unclear risk of bias; therefore, it was not possible to accurately determine the degree of bias of the described treatment effects. Further research should be conducted with well-designed methodological research protocols using random allocation, allocation concealment, assessor blindness, sample sizes calculation, and intention-totreat-respected analyses.

Twenty-one studies were conducted in Korea and one was conducted in Japan. For identifying all potentially relevant researches, the search strategy in the present study included American (PubMed) and European (EMBASE) databases. No attempts were made to retrieve articles from Chinese, Korean, or Japanese databases. Also, non-English articles from PubMed and EMBASE were not included. Because of these, studies may have been excluded. However, when we made our search strategy, we did not expect different results among the countries (Korea, Japan, and China) which conduct a relatively large number of studies on herbs. We assume that the great interest in topical use of herbs and the large number of research and development (R\&D) projects on herbs in Korea have been important factors of the results.

In summary, we have reviewed studies investigating topical herbal application in AD-like animal models. For all studies, we judged most domains to be at unclear risk of bias. Herbs of the genus Chrysanthemum were used in two studies, and seven studies investigated herbs of the clear heat drug group. Among the AD-like animal models, NC/Nga and $\mathrm{BALB} / \mathrm{c}$ mice treated with chemical haptens, DNCB, DNFB, or TNCB were used in most of the studies. Clinical symptoms, serum IgE levels, and Th1- and/or Th2-related cytokines and/or chemokines were assessed as outcome measurements. Among the 22 included studies, 21 herbs were reported to reduce $\mathrm{AD}$-like skin lesions in mouse models by suppressing Th2 cell responses. By summarizing the results from the published literature, we hope that this study might aid in finding a potential herbal therapeutic agent for the treatment of AD. The limitation of this study was that a meta-analysis was not conducted because of the variety of investigated herbs included in the studies. Nevertheless, this review may assist in identifying directions for further researches endeavors.

\section{Conflict of Interests}

The authors state that there is no conflict of interests. No financial support or benefits were received by the authors. The authors have no commercial associations or financial relationships to disclose.

\section{Acknowledgments}

The authors would like to thank Kim Sunre for the helpful discussions. This work was supported by a Grant of the Traditional Korean Medicine R\&D Project, Ministry of Health and Welfare, Republic of Korea (HI12C1889 and HI13C0530).

\section{References}

[1] H. F. Ji, X. J. Li, and H. Y. Zhang, "Natural products and drug discovery: can thousands of years of ancient medical knowledge lead us to new and powerful drug combinations in the fight against cancer and dementia?" EMBO Reports, vol. 10, no. 3, pp. 194-200, 2009.

[2] N. Novak, "New insights into the mechanism and management of allergic diseases: atopic dermatitis," Allergy, vol. 64, no. 2, pp. 265-275, 2009.

[3] J. Verhagen, M. Akdis, C. Traidl-Hoffmann et al., "Absence of T-regulatory cell expression and function in atopic dermatitis skin," Journal of Allergy and Clinical Immunology, vol. 117, no. 1, pp. 176-183, 2006.

[4] W. Abramovits, "Atopic dermatitis," Journal of the American Academy of Dermatology, vol. 53, supplement 1, no. 1, pp. S86S93, 2005.

[5] J. J. Russell, "Topical tacrolimus: a new therapy for atopic dermatitis," The American Family Physician, vol. 66, no. 10, pp. 1899-1903, 2002.

[6] P. Sandercock and I. Roberts, "Systematic reviews of animal experiments," The Lancet, vol. 360, no. 9333, article 586, 2002.

[7] C. R. Hooijmans and M. Ritskes-Hoitinga, "Progress in using systematic reviews of animal studies to improve translational research," PLoS Medicine, vol. 10, no. 7, Article ID e1001482, 2013.

[8] C. R. Hooijmans, A. Tillema, M. Leenaars, and M. RitskesHoitinga, "Enhancing search efficiency by means of a search filter for finding all studies on animal experimentation in PubMed," Laboratory Animals, vol. 44, no. 3, pp. 170-175, 2010.

[9] Y. Y. Sung, T. Yoon, J. Y. Jang, S. J. Park, and H. K. Kim, "Topical application of Rehmannia glutinosa extract inhibits mite allergen-induced atopic dermatitis in NC/Nga mice," Journal of Ethnopharmacology, vol. 134, no. 1, pp. 37-44, 2011.

[10] S. Park, J. B. Lee, and S. Kang, "Topical application of Chrysanthemum indicum L. Attenuates the development of atopic dermatitis-like skin lesions by suppressing serum IgE levels, IFN- $\gamma$, and IL-4 in Nc/Nga mice," Evidence-Based Complementary and Alternative Medicine, vol. 2012, Article ID 821967, 8 pages, 2012.

[11] N. K. Kim, D. H. Lee, H. S. Seo et al., "Hwangryunhaedoktang in adult patients with atopic dermatitis: a randomised, doubleblind, placebo-controlled, two-centre trial-study protocol," BMC Complementary and Alternative Medicine, vol. 11, article 68, 2011.

[12] I. H. Choi, S. Kim, Y. Kim, and Y. Yun, "The effect of TJ15 Plus TJ-17 on atopic dermatitis: a pilot study based on the principle of pattern identification," Journal of Alternative and Complementary Medicine, vol. 18, no. 6, pp. 576-582, 2012.

[13] K. L. Hon, T. F. Leung, P. C. Ng et al., "Efficacy and tolerability of a Chinese herbal medicine concoction for treatment of atopic dermatitis: a randomized, double-blind, placebo-controlled study," The British Journal of Dermatology, vol. 157, no. 2, pp. 357-363, 2007. 
[14] J. K. Lee, H. Ha, H. Y. Lee et al., "Inhibitory effects of heartwood extracts of Broussonetia kazinoki sieb on the development of atopic dermatitis in NC/Nga mice," Bioscience, Biotechnology and Biochemistry, vol. 74, no. 9, pp. 1802-1806, 2010.

[15] S. E. Choi, K. H. Park, M. S. Jeong et al., "Effect of Alnus japonica extract on a model of atopic dermatitis in NC/Nga mice," Journal of Ethnopharmacology, vol. 136, no. 3, pp. 406413, 2011.

[16] G. Yang, K. Lee, M. H. Lee, S. H. Kim, I. H. Ham, and H. Y. Choi, "Inhibitory effects of Chelidonium majus extract on atopic dermatitis-like skin lesions in NC/Nga mice," Journal of Ethnopharmacology, vol. 138, no. 2, pp. 398-403, 2011.

[17] N. R. Ngatu, M. K. Okajima, M. Yokogawa et al., "Antiallergic effects of Vernonia amygdalina leaf extracts in hapteninduced atopic dermatitis-like disease in mice," Allergology International, vol. 61, no. 4, pp. 597-607, 2012.

[18] G. Yang, K. Lee, D.-G. An, M. H. Lee, I. H. Ham, and H. Y. Choi, "Effect of Chrysanthemi borealis flos on atopic dermatitis induced by 1-chloro 2,4-dinitrobenzene in NC/Nga mouse," Immunopharmacology and Immunotoxicology, vol. 34, no. 3, pp. 413-418, 2012.

[19] T. C. Scharschmidt and J. A. Segre, "Modeling atopic dermatitis with increasingly complex mouse models," Journal of Investigative Dermatology, vol. 128, no. 5, pp. 1061-1064, 2008.

[20] H. Matsuda, N. Watanabe, G. P. Geba et al., "Development of atopic dermatitis-like skin lesion with IgE hyperproduction in NC/Nga mice," International Immunology, vol. 9, no. 3, pp. 461466, 1997.

[21] H. Jin, R. He, M. Oyoshi, and R. S. Geha, "Animal models of atopic dermatitis," The Journal of investigative dermatology, vol. 129, no. 1, pp. 31-40, 2009.

[22] H. Lee, J. K. Lee, H. Ha, M. Y. Lee, C. S. Seo, and H. K. Shin, "Angelicae dahuricae radix inhibits dust mite extractinduced atopic dermatitis-like skin lesions in NC/Nga mice," Evidence-Based Complementary and Alternative Medicine, vol. 2012, Article ID 743075, 7 pages, 2012.

[23] U. M. Saarinen, K. Juntunen, M. Kajosaari, and F. Bjorksten, "Serum immunoglobulin E in atopic and non-atopic children aged 6 months to 5 years. A follow-up study," Acta Paediatrica Scandinavica, vol. 71, no. 3, pp. 489-494, 1982.

[24] E. J. Choi, S. Lee, H. H. Kim et al., "Suppression of dust mite extract and 2,4-dinitrochlorobenzene-induced atopic dermatitis by the water extract of Lindera obtusiloba," Journal of Ethnopharmacology, vol. 137, no. 1, pp. 802-807, 2011.

[25] J. S. Hwang, H. K. Kwon, J. E. Kim, J. Rho, and S. H. Im, "Immunomodulatory effect of water soluble extract separated from mycelium of Phellinus linteus on experimental atopic dermatitis," BMC Complementary and Alternative Medicine, vol. 12, article 159, 2012.

[26] D. Y. Leung and T. Bieber, "Atopic dermatitis," The Lancet, vol. 361, no. 9352, pp. 151-160, 2003.

[27] X. F. Qi, D. H. Kim, Y. S. Yoon et al., "Effects of Bambusae caulis in Liquamen on the development of atopic dermatitis-like skin lesions in hairless mice," Journal of Ethnopharmacology, vol. 123, no. 2, pp. 195-200, 2009.

[28] E. H. Sohn, S. A. Jang, C. H. Lee et al., "Effects of Korean red ginseng extract for the treatment of atopic dermatitis-like skin lesions in mice," Journal of Ginseng Research, vol. 35, no. 4, pp. 479-486, 2011.

[29] G. Wu, L. Li, G. H. Sung et al., "Inhibition of 2,4-dinitrofluorobenzene-induced atopic dermatitis by topical application of the butanol extract of Cordyceps bassiana in NC/Nga mice," Journal of Ethnopharmacology, vol. 134, no. 2, pp. 504-509, 2011.

[30] Y.-Y. Sung, T. Yoon, J. Y. Jang, S. J. Park, G. H. Jeong, and H. K. Kim, "Inhibitory effects of Cinnamomum cassia extract on atopic dermatitis-like skin lesions induced by mite antigen in NC/Nga mice," Journal of Ethnopharmacology, vol. 133, no. 2, pp. 621-628, 2011.

[31] D. Y. Nam, J. M. Lee, J. C. Heo, and S. H. Lee, "Mitigation of 2,4-dinitrofluorobenzene-induced atopic dermatitis-related symptoms by Terminalia chebula Retzius," International Journal of Molecular Medicine, vol. 28, no. 6, pp. 1013-1018, 2011.

[32] J. H. Choi, B. H. Park, H. G. Kim et al., "Inhibitory effect of Psidium guajava water extract in the development of 2,4dinitrochlorobenzene-induced atopic dermatitis in NC/Nga mice," Food and Chemical Toxicology, vol. 50, no. 8, pp. 29232929, 2012.

[33] Y. Y. Sung, D. S. Kim, W. K. Yang et al., "Inhibitory effects of Drynaria fortunei extract on house dust mite antigen-induced atopic dermatitis in NC/Nga mice," Journal of Ethnopharmacology, vol. 144, no. 1, pp. 94-100, 2012.

[34] Y. H. Kang and H. M. Shin, "Inhibitory effects of Schizandra chinensis extract on atopic dermatitis in NC/Nga mice," Immunopharmacology and Immunotoxicology, vol. 34, no. 2, pp. 292-298, 2012.

[35] Y. Y. Sung, W. K. Yang, A. Y. Lee et al., “Topical application of an ethanol extract prepared from Illicium verum suppresses atopic dermatitis in NC/Nga mice," Journal of Ethnopharmacology, vol. 144, no. 1, pp. 151-159, 2012.

[36] G. Yang, C. H. Choi, K. Lee, M. Lee, I. Ham, and H. Y. Choi, "Effects of Catalpa ovata stem bark on atopic dermatitis-like skin lesions in NC/Nga mice," Journal of Ethnopharmacology, vol. 145, no. 2, pp. 416-423, 2013.

[37] J. H. Kim, M. H. Kim, G. Yang, Y. Huh, S. H. Kim, and W. M. Yang, "Effects of topical application of Astragalus membranaceus on allergic dermatitis," Immunopharmacology and Immunotoxicology, vol. 35, no. 1, pp. 151-156, 2013.

[38] J. H. Choi, H. G. Kim, S. W. Jin et al., "Topical application of Pleurotus eryngii extracts inhibits 2,4-dinitrochlorobenzeneinduced atopic dermatitis in NC/Nga mice by the regulation of Th1/Th2 balance," Food and Chemical Toxicology, vol. 53, pp. 3845, 2013. 


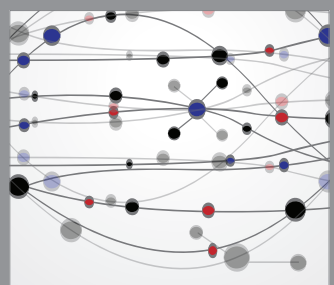

The Scientific World Journal
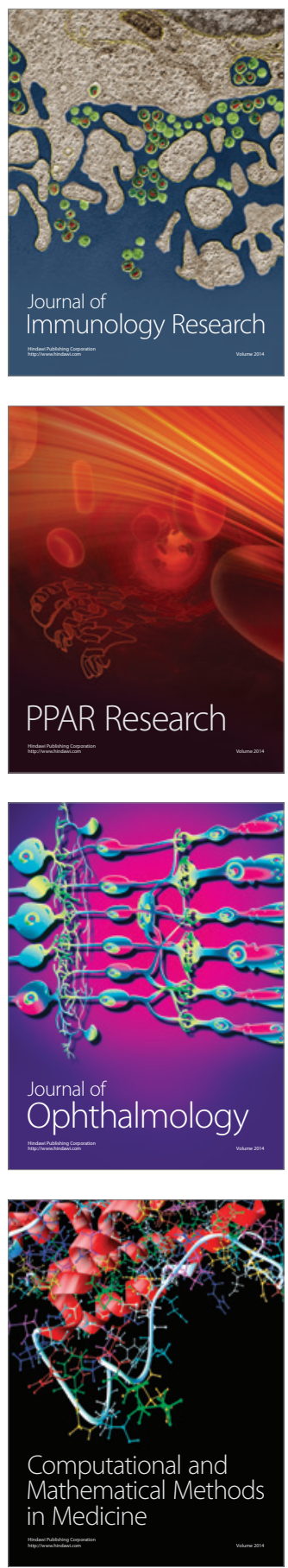

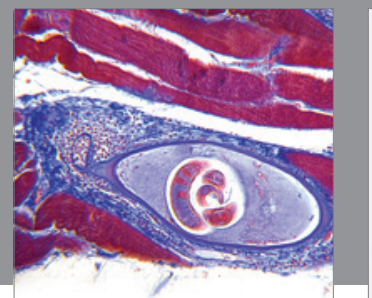

Gastroenterology

Research and Practice
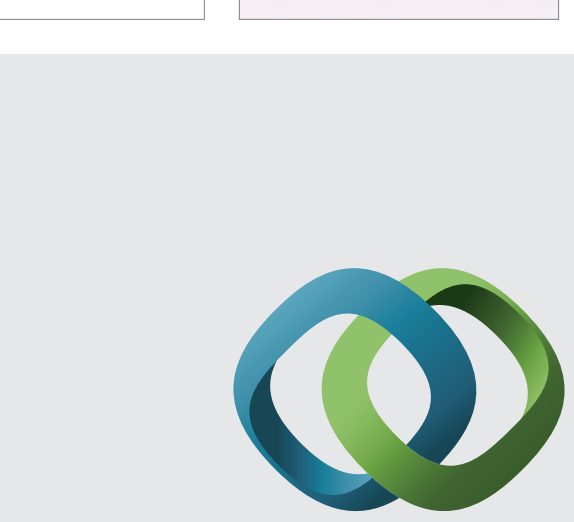

\section{Hindawi}

Submit your manuscripts at

http://www.hindawi.com
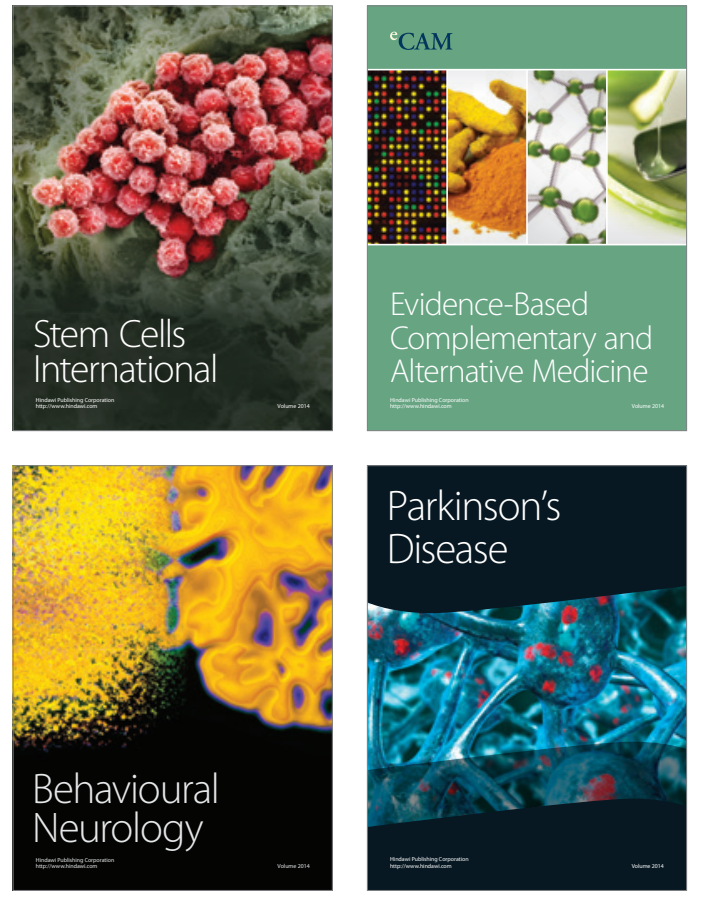
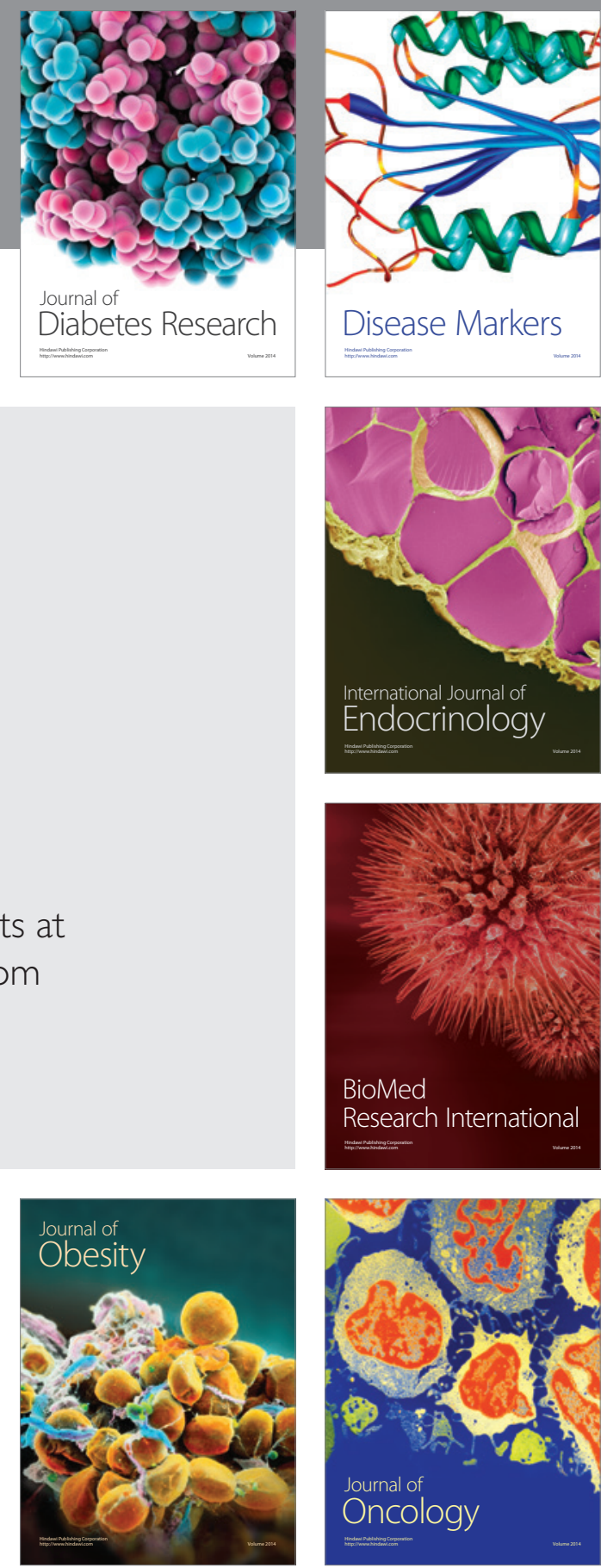

Disease Markers
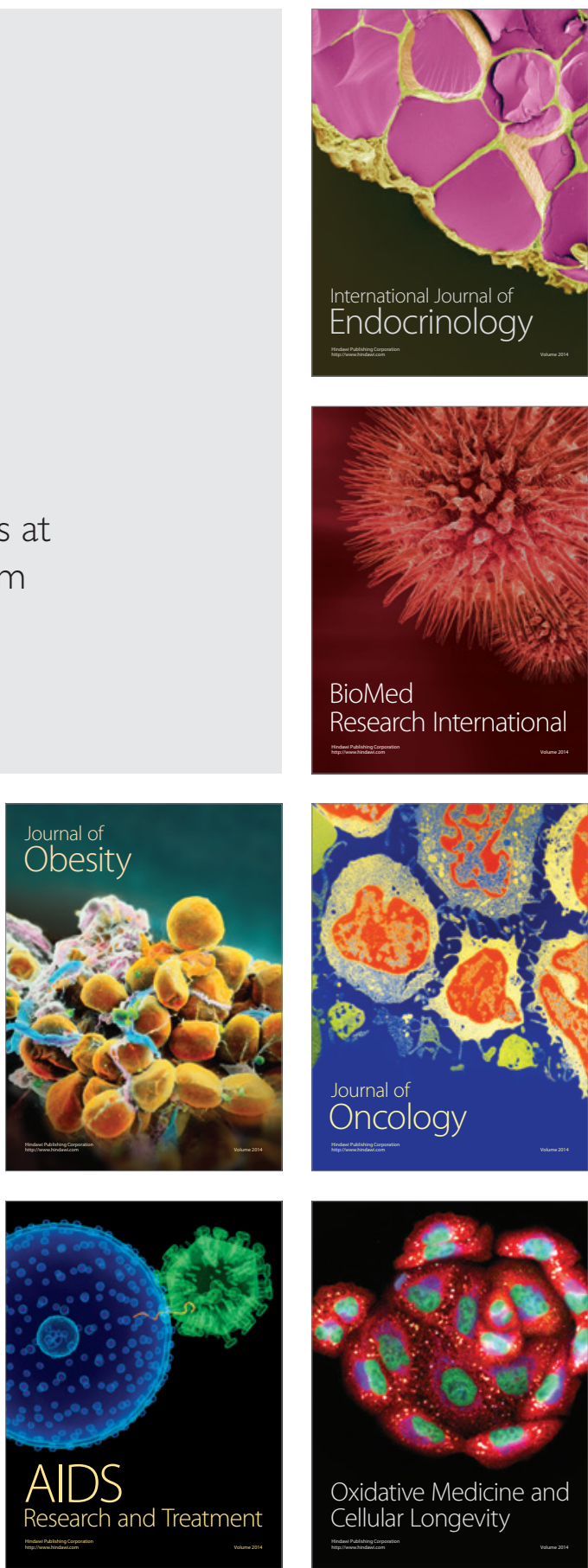